\title{
Recent Research Progress in and Future Perspective on Treatment of Parkinson's Disease
}

\author{
Yoshikuni Mizuno \\ Department of Neurology, Juntendo University School of Medicine, Tokyo, Japan
}

Key Words

Parkinson's disease $\cdot$ Pathogenesis · Clinical features · Treatment $\cdot$ Review

\begin{abstract}
Background: Clinical features, pathogenesis, and treatment of Parkinson's disease (PD) are reviewed as there has been progress in these areas. Summary: PD is a systemic disease of the nervous system as the initial symptom is related to disturbance of the autonomic nervous system, such as constipation or nocturia. Then, the disease progresses to the brain stem involving the nuclei in the pons and the substantia nigra, and inducing sleep and wakefulness disturbances, affect problems such as anxiety and depression, and motor problems when the disease process has reached the substantia nigra. Furthermore, the disease has an effect on the nucleus basalis of Meynert, the amygdaloid complex and the cerebrum manifesting cognitive impairment. The olfactory pathway is also frequently involved. Key Messages: For the treatment of PD, younger patients without dementia should be treated with a nonergot dopamine agonist first and then with levodopa if necessary. Elderly patients or those with dementia should be treated with levodopa. However, after 5 years of levodopa treatment, many patients with PD develop wearing off. Drugs for the treatment of wearing-off symptoms are reviewed. Many of the patients with wearing-off symptoms develop dyskinesia, and amantadine is so far the only drug that can ameliorate dyskinesia. Because of this situation, a new method of treatment is warranted, such as RNA interaction, according to the author's opinion. Recent progress in this field is also reviewed.

(C) 2014 S. Karger AG, Basel
\end{abstract}




\section{Introduction}

Parkinson's disease (PD) was first described by James Parkinson [1]. He published a monograph entitled An Essay on the Shaking Palsy based on the clinical observation of 6 cases, wherein he mentioned most of the symptoms that we see today except for rigidity, which was described by Jean-Martin Charcot [2]. Charcot proposed to call this disease Parkinson's disease, as the description by James Parkinson was so excellent. At that time, dementia was not seen as a main feature of this disease. However, in 1976, Kosaka et al. [3] described a patient who started with symptoms of dementia and parkinsonism that led to diffuse Lewy body disease as shown by the postmortem examination. Lewy body is a cytoplasmic inclusion body characteristic of PD [4]. In 1919, the substantia nigra was considered to be responsible for most of the symptoms of PD [5]. In 2003, Braak et al. [6] studied the distribution of Lewy bodies and suggested that PD starts in the dorsal motor nucleus of the medulla oblongata and that the disease then progresses to the brain stem involving the locus coeruleus and the substantia nigra, and eventually cerebral cortical areas.

\section{Nonmotor Features of PD}

\section{Autonomic Symptoms}

PD starts with nonmotor symptoms [7, 8] (table 1). The first symptom of PD may be constipation starting years to decades before motor symptoms. Not only does the bowel movement decrease but the timing of the bowel movement may also be disturbed; it may occur in the late afternoon or even after dinner. Patients with constipation should be encouraged to eat fresh vegetables and drink a glass of water three times a day at meals and to take a laxative before going to sleep. Nocturia is also observed before the motor symptoms. Symptomatic orthostatic hypotension is not common but can be seen. Hypotensive patients should eat salty foods and drink water. For patients with symptomatic orthostatic hypotension, midodrine, amidinium or fludrocortisone can be prescribed [9].

\section{Hyposmia}

Olfactory function in PD patients was explored by Ansari and Johnson [10] in 1975. They studied 22 patients with PD and found a loss of olfactory function. Since then, many authors have reported similar results. Hyposmia in PD is not related to the duration or the stages of the disease, or medication [11]. It usually precedes the onset of PD [12] and may be seen in more than $80 \%$ of PD patients [13]. Hyposmia in PD appears to be the result of marked dopaminergic deficiency in the olfactory tubercle and loss of dopaminergic innervation from the mesencephalon to the piriform cortex [14]. However, in the olfactory bulb, dopaminergic neurons seem to be increased; normally dopamine in the olfactory bulb suppresses the olfactory information [15]. Severe hyposmia in PD appears to be a forerunner of subsequent dementia [16].

\section{Sleep Disorder}

Insomnia, restless legs syndrome, and rapid-eye movement sleep behavior disorder (RBD) are three major causes of sleep disorders in PD. Patients with PD may have difficulty in falling asleep. Depression or anxiety, or pain related to dystonia or other complications may cause insomnia. A sleeping pill, an antidepressant or a dopamine agonist can be prescribed at bedtime.

Restless legs syndrome is a condition characterized by discomfort at rest and the urge to move the legs [17]. It is a cause of insomnia. A small amount of a dopamine agonist can be 
Mizuno et al.: Recent Research Progress in and Future Perspective on Treatment of Parkinson's Disease

Table 1. Nonmotor symptoms of PD

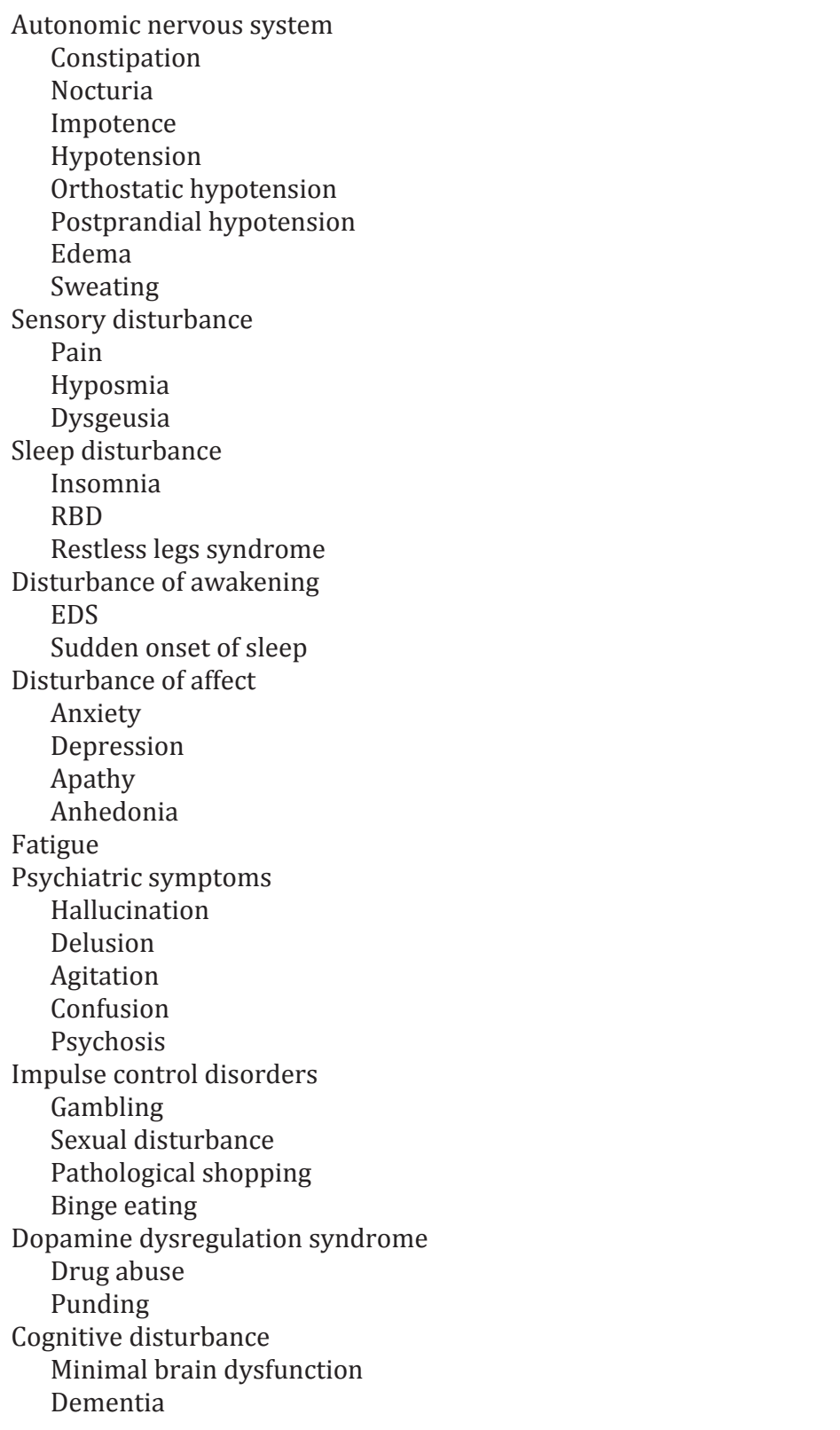

given at bedtime. In case the dopamine agonist is not effective enough, a small amount of levodopa, clonazepam, sodium valproate or gabapentin may also be prescribed.

RBD is characterized by prominent motor behaviors and loss of muscular atonia during rapid-eye movement sleep; it may be seen in about 30\% of patients with PD [18]. RBD is usually observed before the onset of motor symptoms. Schenck et al. [19] reported that 38\% of 29 older men initially diagnosed with idiopathic RBD developed PD after a mean of $12.7 \pm$ 7.3 years from the onset of RBD. For the accurate diagnosis of RBD, polysomnography is necessary, but convenient questionnaires have also been reported [20]. RBD seems to be the result of a lack of dopaminergic stimulation to the pontine nuclei near the locus coeruleus [21]. For the treatment of RBD, clonazepam (0.5-2 mg) at bedtime is effective. However, if it does not work, levodopa, a dopamine agonist, or donepezil can be given. Also, patients are 
instructed not to take an antidepressant or chocolate. There is a correlation between RBD and loss of olfaction [22] and loss of MIBG uptake to the cardiac sympathetic nerves [23]. Also, loss of olfaction is correlated with loss of cardiac MIBG uptake [24]. Therefore, these will be early markers of PD [25].

\section{Disturbance of Wakefulness}

Excessive daytime sleepiness (EDS) is seen in about one third of patients with PD [26]. Sleep attacks are episodes of falling asleep without warning signs of drowsiness. Both of them are related to the treatment with dopamine agonists [27]. However, EDS and sleep attacks may occur without the use of a dopamine agonist. The use of levodopa and the pathophysiology of PD itself appear to be causes of sleepiness [28]. EDS is more severe in demented patients. Videnovic et al. [29] measured serum melatonin every $30 \mathrm{~min}$ in PD patients and controls, and found a marked decrease of serum melatonin in patients with PD. Furthermore, in patients with EDS, serum melatonin was significantly lower than in those patients with PD who did not have EDS. They suggested that timed exposure to bright light and exercise might help against EDS. Modafinil is only partially effective against EDS [30]. Therefore, due care is necessary when a dopamine agonist is prescribed. Patients on a dopamine agonist should not drive a car until it has become clear that the dopamine agonist does not cause EDS.

\section{Disturbance of Affect}

About one third of the patients with PD have anxiety disorders. Female sex, the presence of motor fluctuations, and a previous history of an anxiety disorder are risk factors for anxiety disorders [31]. Patients may ask 'Is this disease curable?', 'Do I lose the job?', 'May drugs I am taking become ineffective within a few years?', 'Will I become unable to walk?', and 'May our children get the disease as well?'. In answering these questions, an optimistic attitude is important. About $90-95 \%$ of PD cases are sporadic, and familial PD is usually much easier to treat except for rare cases of PARK9 or PARK14.

\section{Depression}

Depression is seen in PD in about one fourth to one third of the patients [8, 32, 33]. It is related not only to serotonergic dysfunction but also to noradrenergic, dopaminergic, and acetylcholinergic dysfunctions. Drug treatment of depression in PD should not be considered the same as treatment of major depression. Controversial results have been reported on selective serotonin reuptake inhibitors [34, 35]. Tricyclic antidepressants seem to be better for depression in PD [35]. However, due care is important for anticholinergic effects. A mild antidepressive effect may be seen in PD patients treated with pramipexole [36, 37].

\section{Hallucination and Delusion}

Usually hallucinations and delusions are considered to be side effects of anti-PD drugs. An initial symptom of hallucinations may be a feeling of the existence of other persons, or the patient may see an animal feature when he or she is going to the toilet at night. A clock on the wall may be seen as if representing a human being's face. However, when the patient stares at the object, visual hallucinations soon disappear. The patient understands that he or she is seeing a hallucination and no coherent behavior guided by the hallucination is observed. No treatment is necessary at this stage, unless visual hallucinations occur frequently. If this is the case, the patient may see hallucinations during daytime as well, and they also tend to last longer. At this stage, treatment is necessary. In more advanced cases, the patients may behave incoherently guided by the hallucination. They may lose orientation and psychosis sets in. The patients may have a delusional ideation such as that they were stolen by the purse. In the 
PD patients with dementia, hallucinations and delusions may become more severe, and the psychotic state may continue all day long. Progression of PD may make the brain liable to develop hallucinations and delusions [38].

Treatment of hallucination, delusion, and psychosis includes discontinuing the last drug that has been added or changing the dosage. If this does not alleviate or reduce hallucination, then anti-PD drugs should be discontinued in the following order: anticholinergics, amantadine, monoamine oxidase B (MAOB) inhibitor, catechol-0-methyltransferase inhibitor, zonisamide, istradefylline, and the dopamine agonist. Levodopa dose can be reduced. If this strategy does not work well, then donepezil should be given [39]. Quetiapine is frequently used for hallucination, delusion, and psychosis; however, a double-blind study did not show any beneficial effect on hallucination [40]. Clozapine for psychosis [41] can be used with due care for agranulocytosis.

\section{Impulse Control Disorder and Dopamine Dysregulation Syndrome}

These are complications of dopamine agonists or levodopa in relatively young PD patients. Readers who are interested in this topic should consult the following articles by O'Sullivan et al. [42] and Voon et al. [43].

\section{Cognitive Impairment}

The cross-sectional prevalence of cognitive deficits in PD is close to 30\% [44], and the prevalence rises if one can follow the patients until their death. Readers who are interested in dementia in PD should consult the following articles by Emre et al. [44] and Goldman and Holden [45]. Dementia with Lewy bodies is a condition in which dementia appears before the motor symptoms or it occurs simultaneously with the motor symptoms. Readers who are interested in dementia with Lewy bodies should consult the following articles by McKeith et al. [46] and Rongve et al. [47].

\section{Motor Features of PD}

\section{Initial Symptoms}

Motor features of PD consist of resting tremor, rigidity, bradykinesia, and loss of postural reflex. About $50 \%$ of PD patients start with a unilateral tremor, mainly in the hand but occasionally in the leg according to our observation. Tremor may be seen in up to $70-80 \%$ of cases in the course of the disease. About $30 \%$ of the patients start with a unilateral shuffling gait and the rest of the patients start with unilateral bradykinesia-related symptoms in an arm such as having difficulty in handwriting or in changing clothes. Within 1-3 years, symptoms of PD will become bilateral, but the asymmetry of symptoms will continue. At a late stage, after more than 15-20 years from onset, the asymmetry of symptoms may become less prominent.

\section{Motor Fluctuations}

Two to five years after the start of levodopa treatment, many patients with PD have wearing-off fluctuations, meaning that the beneficial effect of levodopa may last only 2-3 $\mathrm{h}$. Patients with PD may also have dyskinesia (mainly choreic, at times dystonic, athetoid, or myoclonic movements) when levodopa is working. At times, patients with PD may have diphasic dyskinesia, which appears in the rising phase and descending phase of blood levodopa levels; diphasic dyskinesia is prominently seen in the legs but it may also occur in the arms and the trunk. The movement is coarse tremor-like, dystonia-like, vigorous, and stereotypic. Diphasic dyskinesia usually ceases spontaneously after 20-30 min. 


\section{Advanced Stage}

In the course of PD, those patients who need levodopa and are fluctuating are called advanced-stage patients. This stage may start approximately 5 years after the initiation of levodopa treatment. In a more advanced stage, 10 years or more after the initiation of levodopa, patients with PD may have a shuffling gait even during the 'on' stage and they may fall down due to a stuttering or freezing gait or due to festination with injuries including fractures. Freezing of gait occurs mainly at home while the patients are in 'off' states. But it may also occur during 'on' states. Festination is a similar phenomenon, which may occur outside the home as well. There is no good drug against freezing and festination. Patients with PD are encouraged to raise the knees while walking so that the tips of the toes will be raised as well. If they are thinking of something else while walking, the gait may become shuffling.

Another difficulty encountered at this stage is the drooling. The saliva output is not increased in PD, rather it is decreased [48]. The reason why normal persons do not have drooling is that they swallow saliva unconsciously. Therefore, patients with PD are encouraged to swallow the saliva consciously. For patients with PD, it is very difficult to do any movement unconsciously. Also, patients with PD should be instructed not to be affected by aspiration pneumonia, intestinal obstruction, fractures, and malignant syndrome.

\section{Treatment of PD}

\section{Early-Stage Patients}

The currently available anti-PD drugs (table 2) are all symptomatic. Therefore, drug treatment should be started when the disability of the patient reaches a certain level, at which it has a considerable effect on daily life. This may vary greatly among different patients. A younger patient who is a computer programmer may find it hard to use a computer keyboard if he has slight difficulty in moving his fingers, whereas a retired elderly man may not have difficulty in performing activities of daily living even if he does them more slowly. If a physician decides to initiate treatment, the merits and demerits of levodopa and dopamine agonists must be explained to the patient beforehand.

The drug to be used at the beginning of treatment of PD is either levodopa or a dopamine agonist. If the patient is relatively young, below the age of 65-70, a dopamine agonist may be the starting drug. If the patient is above 70, then levodopa is the first choice. If the patient additionally has dementia, the starting drug is always levodopa. Two classes of dopamine agonists are available: ergot and nonergot dopamine agonists. The ergot dopamine agonists have an ergot structure. They may cause the thickening of the cardiac valves resulting in regurgitation of those valves [49]. Today, a nonergot dopamine agonist is the first choice for younger patients without dementia. The starting dose and the maximum daily dose are shown in table 2. Long-acting forms have also been developed. Apomorphine injection is used only in a rescue treatment for akinetic episodes or freezing of gait. Dopamine agonists usually do not produce wearing off or dyskinesia when used without levodopa. However, they may cause nausea, anorexia, pretibial edema, hallucination, and EDS among others. At times, they may also induce Pisa syndrome or camptocormia. Therefore, due care is necessary when a dopamine agonist is prescribed. In case levodopa and a dopamine agonist do not produce a satisfactory improvement, a MAOB inhibitor (selegiline or rasagiline), a NUDA antagonist (amantadine $\mathrm{HCl}$ ), or a small amount of an anticholinergic drug can be added. The monoamine oxidase inhibitors can be used at a very early stage of the disease, when a patient does not want a stronger drug. 
Mizuno et al.: Recent Research Progress in and Future Perspective on Treatment of Parkinson's Disease

Table 2. Anti-PD drugs

\begin{tabular}{|c|c|c|c|}
\hline Class & Generic name & $\begin{array}{l}\text { Daily maintenance } \\
\text { dose, mg }\end{array}$ & Contraindication, side effect \\
\hline $\begin{array}{l}\text { Precursor of } \\
\text { dopamine }\end{array}$ & $\begin{array}{l}\text { Levodopa }+ \\
\text { carbidopa } \\
\text { Levodopa }+ \\
\text { benserazide }\end{array}$ & $300-900$ & $\begin{array}{l}\text { Side effects: nausea, vomiting, anorexia, constipation, } \\
\text { orthostatic hypotension, edema, dyskinesia, hallucination, } \\
\text { delusion, agitation, confusion, hemolytic anemia, leukopenia, } \\
\text { thrombopenia, liver dysfunction }\end{array}$ \\
\hline $\begin{array}{l}\text { Dopamine } \\
\text { agonist }\end{array}$ & $\begin{array}{l}\text { Pramipexole-LA } \\
\text { Pramipexole } \\
\text { Ropinirole CR } \\
\text { Ropinirole } \\
\text { Rotigotine } \\
\text { Apomorphine } \\
\text { Bromocriptine } \\
\text { Pergolide } \\
\text { Cabergoline }\end{array}$ & $\begin{array}{l}1.5-4.5 \\
1.5-4.5 \\
6-24 \\
6-24 \\
9-36 \text { (applied } \\
\text { dose) } \\
30 \\
7.5-30 \\
0.5-3 \\
1-3\end{array}$ & $\begin{array}{l}\text { Contraindications: toxemia of pregnancy, postpartum } \\
\text { hypertension, pregnant women } \\
\text { Side effects: anorexia, nausea, vomiting, hallucination, } \\
\text { delusion, agitation, confusion, EDS, sudden onset of sleep, } \\
\text { orthostatic hypotension, edema, skin eruption, leukopenia, } \\
\text { thrombopenia; for ergot dopamine agonists, cardiac } \\
\text { valvulopathy, pulmonary, cardiac, retroperitoneal fibrosis }\end{array}$ \\
\hline MAOB inhibitor & $\begin{array}{l}\text { Selegiline } \\
\text { Rasagiline }\end{array}$ & $\begin{array}{l}5-10 \\
0.5-1\end{array}$ & $\begin{array}{l}\text { Side effects: hallucination, delusion, confusion, dyskinesia, } \\
\text { serotonin syndrome when coadministered with tricyclic } \\
\text { antidepressant, liver damage }\end{array}$ \\
\hline COMT inhibitor & Entacapone & $300-1,200$ & Side effects: dyskinesia, anorexia, liver damage, yellow urine \\
\hline Antiepileptics & Zonisamide & $25-50$ & Side effects: drowsiness, ataxia, nausea, vomiting \\
\hline $\mathrm{A}_{2 \mathrm{~A}}$ antagonist & Istradefylline & $20-40$ & Side effects: dystonia, dyskinesia, drowsiness, constipation \\
\hline $\begin{array}{l}\text { Glutamate } \\
\text { antagonist }\end{array}$ & Amantadine & $100-300$ & $\begin{array}{l}\text { Contraindication: narrow-angle glaucoma } \\
\text { Side effects: hallucination, delusion, livedo reticularis, nausea, } \\
\text { dry mouth }\end{array}$ \\
\hline Anticholinergic & $\begin{array}{l}\text { Trihexyphenidyl } \\
\text { Biperidine }\end{array}$ & $\begin{array}{l}2-6 \\
1-3\end{array}$ & $\begin{array}{l}\text { Contraindications: narrow-angle glaucoma, myasthenia gravis, } \\
\text { urinary obstruction } \\
\text { Side effects: dry mouth, constipation, nausea, vomiting, } \\
\text { hallucination, delusion confusion, agitation, loss of memory, } \\
\text { dysuria, loss of accommodation }\end{array}$ \\
\hline $\begin{array}{l}\text { Precursor of } \\
\text { noradrenaline }\end{array}$ & Doroxydopa & $300-900$ & $\begin{array}{l}\text { Contraindications: narrow-angle glaucoma, pregnant women } \\
\text { Side effects: anorexia, hallucination, delusion, hypertension }\end{array}$ \\
\hline
\end{tabular}

\section{Advanced-Stage PD Patients}

Advanced-stage PD patients are those who require levodopa and have motor fluctuations. Wearing off is the first symptom to appear after initiation of levodopa, which usually occurs after 5 years, but may also be seen within 2-3 years. During the 'off' stage, many of the motor symptoms and some of the nonmotor symptoms appear. Usually the 'off' period occurs late in the afternoon before dinner. Such patients are usually already taking a dopamine agonist in addition to levodopa; therefore, the next drug to use is either entacapone or selegiline. One may also use zonisamide or istradefylline, if available.

\section{Wearing Off}

Entacapone is a catechol-0-methyltransferase inhibitor that inhibits 0-methylation of levodopa in peripheral tissues [50]. Entacapone does not cross the blood-brain barrier. 
Therefore, it increases the levodopa level that is taken up into the brain. Thus, the beneficial effect of levodopa may last approximately 30 min longer than that of levodopa alone. At each dose of levodopa, entacapone is coadministered. The dose of entacapone is 100-200 $\mathrm{mg}$ at each time. A combined tablet of levodopa, carbidopa, and entacapone is marketed in some countries; however, using the combined tablet in de novo PD patients increases dyskinesia [51].

When entacapone is not working well, selegiline can be used. Selegiline is an irreversible MAOB inhibitor. MAOB is expressed in serotonergic and glial cells; MAOA is expressed in dopaminergic neurons [52]. In advanced PD, levodopa appears to be taken up into serotonergic and glial cells where it is metabolized to dopamine. Therefore, MAOB inhibitors appear to inhibit metabolism of dopamine. Selegiline may aggravate levodopa-induced dyskinesia. It has a mild anti-PD effect when used in de novo patients [53].

Rasagiline is a newer irreversible MAOB inhibitor, which was tested for disease-modifying effects in PD; $1 \mathrm{mg}$ per day was disease modifying, whereas $2 \mathrm{mg}$ were symptomatic [54]. Therefore, further studies are needed.

Zonisamide is an antiepileptic. A PD patient who had a seizure was given zonisamide, and thereafter his wearing-off symptoms improved. A double-blind study in Japan proved its anti-PD effect. Taking 25-100 mg of zonisamide after breakfast or lunch improved 'on' stage parkinsonism and induced a shortening of the 'off' period [55]. The mode of action is not known.

Istradefylline is an antagonist of adenosine receptors. Adenosine $A_{2 \mathrm{~A}}$ receptors are expressed presynaptically on the GABAergic neurons in the striatum and presynaptically on the indirect strioexternal pallidal pathways [56]. Indirect strioexternal pallidal pathways in PD are hyperactive because of the lack of dopamine causing bradykinesia. By blocking adenosine $\mathrm{A}_{2 \mathrm{~A}}$ receptors with istradefylline, the strioexternal pallidal pathway recovers more normal tone. Double-blind studies in the USA and in Japan revealed improvement of the 'on time' symptoms and shortening of the 'off' period as measured using patients' diaries [5760]. Istradefylline can be given at a dose of $20 \mathrm{mg}$ after breakfast or $20 \mathrm{mg}$ after breakfast and dinner.

For wearing off, traditional anti-PD drugs can also be used. Amantadine is given at a dose of 50-100 mg twice a day after breakfast and lunch and/or trihexyphenidyl $2 \mathrm{mg}$ is administered after breakfast or after breakfast and lunch.

In case these medications do not work on wearing off, the number of times of levodopa intake should be increased. In this case, one should take into account how long the effects of a single dose of levodopa would last. Considering how long levodopa would be effective, levodopa should be given every 2-4 h during the awake time. You may also give levodopa at night when the patient wakes up and needs to go to the toilet. Taking levodopa at night may improve early-morning akinesia and related symptoms such as muscle ache. The patient may take 100-200 mg of levodopa on an empty stomach depending on how much levodopa is necessary for improvement to appear. In case even $100 \mathrm{mg}$ of levodopa causes dyskinesia, the levodopa dose must be decreased.

'No-On' and 'Delayed On'

'No-on' means no clinical benefit after taking levodopa and 'delayed on' means delay in the clinical improvement 30 min or more after taking levodopa. 'No-on' and 'delayed on' are observed due to a delay in intestinal absorption of levodopa. Levodopa is an amino acid; therefore, it is absorbed in the upper jejunum by neutral amino acid transporters. If the patient with PD takes levodopa after the meal, amino acids derived from the protein in the food may interfere with the absorption of levodopa as well as the transport to the brain. This seems to be the main cause of 'no-on' and 'delayed on'. Therefore, levodopa should be given before the meal. 


\section{Peak-Dose Dyskinesia}

Dyskinesia is a choreic or dystonic movement that is seen when levodopa is working [61]. It may appear 2-3 years after the start of levodopa and becomes more prominent as the maintenance dose of levodopa increases according to the progress of the disease. Usually dyskinesia does not interfere with daily activities but at times it becomes prominent interfering with various activities of the PD patients, and then they may feel fatigue because of severe dyskinesia. Such severe dyskinesia is called intractable dyskinesia. Patients with PD may not notice the presence of dyskinesia at all unless it becomes prominent. However, family members notice even the slightest dyskinesia.

Treating dyskinesia means reducing or discontinuing drugs. At first, selegiline should be discontinued as it may increase the severity of dyskinesia. The next thing to do is to discontinue COMT inhibitors, zonisamide, istradefylline, and anticholinergics. There is no suggestion as to which drug should be discontinued first. When a dopamine agonist is used together with levodopa, it will increase the severity of dyskinesia. Continuing a dopamine agonist while decreasing levodopa seems to be one of the ways of treating dyskinesia. However, decreasing levodopa may aggravate the symptoms of PD. In this case, continuing levodopa and decreasing the dopamine agonist can be tried. Sometimes each dose of levodopa must be below $100 \mathrm{mg}$; in this case, dissolve the total daily amount of levodopa in $500 \mathrm{ml}$ of mineral water and take a small part each time at more frequent dosing such as every $2 \mathrm{~h}$ or every $1.5 \mathrm{~h}$. If all these methods fail to treat dyskinesia, a large amount of amantadine (300-400 mg per day) may be of help. Amantadine is the only drug that may decrease 'on time' dyskinesia [62]. But the antidyskinetic effect of amantadine may not last more than 6-12 months. In such cases, subthalamic deep brain stimulation is recommended if the patient is below 75 and does not have dementia. Furthermore, continuous duodenal infusion of levodopa may also be helpful [63].

\section{Diphasic Dyskinesia}

This is a more stereotypic vigorous abnormal involuntary movement involving mainly the legs, but the arms, face, neck, and trunk may also be involved. Vigorous tremor-like movement of both legs is a typical symptom of diphasic dyskinesia. Dystonic movement may also be seen in the legs and the remaining parts of the body.

Diphasic dyskinesia occurs 15-20 min after taking levodopa and lasts 20-30 min. It may also be seen when the drug effects on PD wears off. It may not be seen every time after levodopa ingestion. There is no good drug for the treatment of diphasic dyskinesia. At times, no treatment is necessary as the duration of dyskinesia is not long enough. In more severe cases, one can try a large amount of amantadine. STNDBS may also be effective.

\section{Pathogenesis of PD}

Two lines of biochemical abnormalities are known: one is mitochondrial deficiency of complex I and the other is accumulation of $\alpha$-synuclein aggregates. Mitochondrial deficiency of complex I was first reported by Schapira et al. [64] in 1989. We reported deficiency of complex I proteins by immunoblotting in striatal mitochondria in the same year [65], whereas accumulation of $\alpha$-synuclein aggregates in Lewy bodies was first reported in 1997 [66]. However, the relation between complex I deficiency and $\alpha$-synuclein aggregation was not clear until 2008, when Devi et al. [67] reported an increase of mitochondrial $\alpha$-synuclein in PD and inhibition of the nigral complex I by $\alpha$-synuclein but not in the cerebellum. In control patients, mitochondrial $\alpha$-synuclein was not increased.

Therefore, the pathogenesis of PD may be summarized as shown in figure 1. For unknown reasons, $\alpha$-synuclein in PD tends to undergo polymerization. At first, oligomers of $\alpha$-synuclein, 
Mizuno et al.: Recent Research Progress in and Future Perspective on Treatment of Parkinson's Disease

Fig. 1. Schematic presentation of the pathogenesis of PD. $\alpha$-Synuclein undergoes oligomer formation and polymerization. Oligomers of $\alpha$-synuclein induce oxidative stress and impairment of membranous structures such as $26 \mathrm{~S}$ proteasome, mitochondria, and microsomes. Polymerized $\alpha$-synuclein is thought to interfere with the axonal transport of important materials for neurons. Also, part of $\alpha$-synuclein is believed to enter the mitochondria in PD and to inhibit complex I contributing to neuronal death.

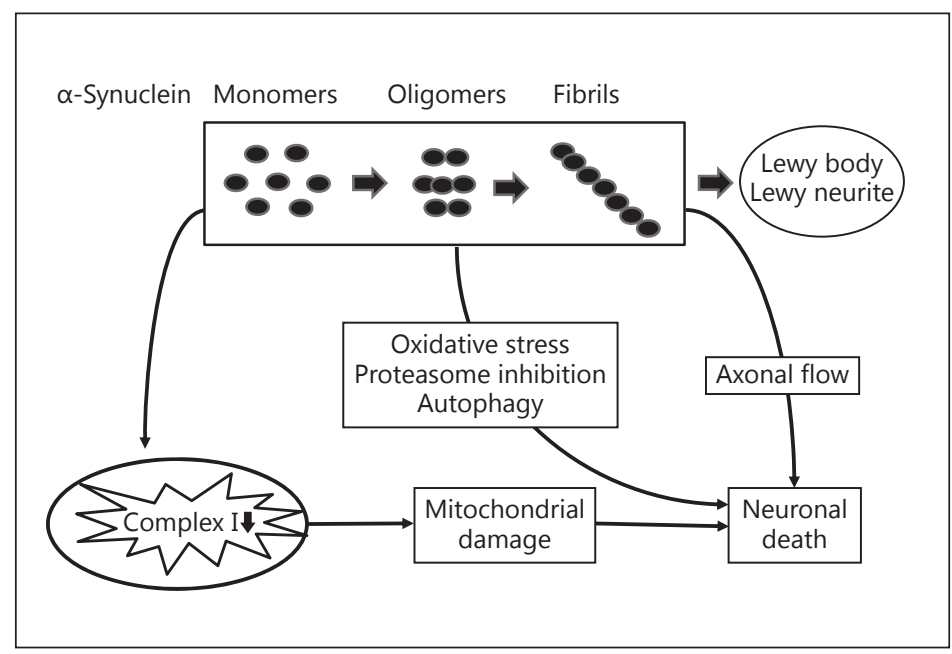

still having a soluble character, seem to increase oxidative stress, disturbance of membranous structures such as mitochondrial membranes or microsomal membranes, and impairment of $26 \mathrm{~S}$ proteasome [68]. Finally, $\alpha$-synuclein develops into insoluble aggregates. Insoluble aggregates of $\alpha$-synuclein in dendrites and axons may interfere with the transport of various important substances. Inhibition of complex I may aggravate the degenerative process and, together with the aggregation of $\alpha$-synuclein, enhance it. Thus the future treatment of PD must be directed to the inhibition of $\alpha$-synuclein aggregation.

\section{Is Disease Protection Possible?}

Many ways of disease-modifying treatments have been attempted, but none of them proved effective in PD patients. Therefore, we must find a new method of treatment. RNA interaction seems to be a possibility. Here, RNA interaction utilizes 20 mer RNA to inhibit a specific allele of mRNA. In autosomal dominant disease, only one allele is abnormal. By introducing a specific RNA to inhibit the only abnormal allele of RNA, one can inhibit abnormal protein synthesis. This has been tried in many autosomal dominant disorder models such as SOD1-mutated amyotrophic lateral sclerosis [69], Huntington's disease transgenic animals [70], APP-mutated Alzheimer transgenic animals [71], and ataxin-3-mutated Machado-Joseph transgenic animals [72]. In these experiments, RNAs were injected directly into organs or intrathecally.

To use this method in human diseases, RNA must be bound to a highly neuron-specific substance. Kumar et al. [73] reported that a small RNA connected to the rabies glycoprotein was delivered to the central nervous system. After they had created green fluorescent transgenic animals, they administered small RNA against green fluorescence connected to the rabies glycoprotein into the tail vein of the transgenic animals. After that they measured the green fluorescence of each organ by flow cytometry. There was no decrease in the green fluorescence in the spleen or the liver, whereas there was approximately $30 \%$ decrease of green fluorescence in the brain indicating inhibition of the fluorescence material in the brain. To use this method in human diseases, it will be necessary to develop much safer materials to attach RNA. By doing so, aggregations of $\alpha$-synuclein may in part be inhibited. 


\section{Disclosure Statement}

The author has no conflict of interest.

\section{References}

1 Parkinson J: An Essay on the Shaking Palsy. London, Sherwood, Neely, and Jones, 1817, pp 1-66.

2 Charcot J-M: Leçons du mardi à la Salpêtrière (1887-1888). Paris, Bureaux du Progrès Médical, 1887.

-3 Kosaka K, Oyanagi S, Matsushita M, Hori A: Presenile dementia with Alzheimer-, Pick- and Lewy-body changes. Acta Neuropathol (Berl) 1976;36:221-233.

4 Lewy FH: Paralysis agitans; in Lewndowsky M (ed): Pathologische Anatomie. Handbuch der Neurologie. Berlin, Springer, 1912, vol 3: Spezielle Pathologie II, pp 920-933.

5 Trétiakoff C: Contribution à l'étude de l'anatomie pathologique du locus niger; thesis, University of Paris, 1919.

-6 Braak H, Del Tredici K, Rüb U, de Vos RAI, Jansen Steur ENH, Braak E: Staging of brain pathology related to sporadic Parkinson's disease. Neurobiol Aging 2003;24:197-211.

7 Chaudhuri KR, Martinez-Martin P, Schapira AHV, Stocchi F, Sethi K, Odin P: International multicenter pilot study of the first comprehensive self-completed nonmotor symptoms questionnaire for Parkinson's disease: the NMSQuest Study. Mov Disord 2006;21:916-923.

8 Barone P, Antonini A, Colosimo C, Marconi R, Morgante L, Avarello TP, et al: The PRIAMO study: a multicenter assessment of nonmotor symptoms and their impact on quality of life in Parkinson's disease. Mov Disord 2009;24:1641-1649.

-9 Senard JM, Brefel-Courbon C, Rascol O, Montastruc JL: Orthostatic hypotension in patients with Parkinson's disease: pathophysiology and management. Drugs Aging 2001;18:495-505.

10 Ansari KA, Johnson A: Olfactory function in patients with Parkinson's disease. J Chronic Dis 1975;28:493-497.

11 Doty RL, Deems DA, Stellar S: Olfactory dysfunction in parkinsonism: a general deficit unrelated to neurologic signs, disease stage, or disease duration. Neurology 1988;38:1237-1244.

12 Berendse HW, Booij J, Francot CM, Bergmans PL, Hijman R, Stoof JC, et al: Subclinical dopaminergic dysfunction in asymptomatic Parkinson's disease patients' relatives with a decreased sense of smell. Ann Neurol 2001;50: $34-41$.

13 Silveira-Moriyama L, Carvalho Mde J, Katzenschlager R, Petrie A, Ranvaud R, Barbosa ER, et al: The use of smell identification tests in the diagnosis of Parkinson's disease in Brazil. Mov Disord 2008;23:2328-2334.

14 Liberini P, Parola S, Spano PF, Antonini L: Olfaction in Parkinson's disease: methods of assessment and clinical relevance. J Neurol 2000;247:88-96.

15 Huisman E, Uylings HB, Hoogland PV: A 100\% increase of dopaminergic cells in the olfactory bulb may explain hyposmia in Parkinson's disease. Mov Disord 2004;19:687-692.

16 Baba T, Kikuchi A, Hirayama K, Nishio Y, Hosokai Y, Kanno S, et al: Severe olfactory dysfunction is a prodromal symptom of dementia associated with Parkinson's disease: a 3 year longitudinal study. Brain 2012;135:161169.

17 Brindani F, Vitetta F, Gemignani F: Restless legs syndrome: differential diagnosis and management with pramipexole. Clin Interv Aging 2009;4:306-313.

18 Gagnon JF, Postuma RB, Mazza S, Doyon J, Montplaisir J: Rapid-eye-movement sleep behaviour disorder and neurodegenerative diseases. Lancet Neurol 2006;5:424-432.

-19 Schenck CH, Bundlie SR, Mahowald MW: Delayed emergence of a parkinsonian disorder in 38\% of 29 older men initially diagnosed with idiopathic rapid eye movement sleep behaviour disorder. Neurology 1996;46: 388-393.

20 Stiasny-Kolster K, Mayer G, Schäfer S, Möller JC, Heinzel-Gutenbrunner M, Oertel WH: The REM sleep behavior disorder screening questionnaire - a new diagnostic instrument. Mov Disord 2007;22:2386-2393.

21 Boeve BF, Silber MH, Saper CB, Ferman TJ, Dickson DW, Parisi JE, et al: Pathophysiology of REM sleep behaviour disorder and relevance to neurodegenerative disease. Brain 2007;130:2770-2788.

-22 Stiasny-Kolster K, Doerr Y, Möller JC, Höffken H, Behr TM, Oertel WH, et al: Combination of 'idiopathic' REM sleep behaviour disorder and olfactory dysfunction as possible indicator for alpha-synucleinopathy demonstrated by dopamine transporter FP-CIT-SPECT. Brain 2005;128:126-137.

23 Nomura T, Inoue Y, Högl B, Uemura Y, Kitayama M, Abe T, et al: Relationship between (123)I-MIBG scintigrams and REM sleep behavior disorder in Parkinson's disease. Parkinsonism Relat Disord 2010;16:683-685.

24 Lee PH, Yeo SH, Kim HJ, Youm HY: Correlation between cardiac ${ }^{123}$ I-MIBG and odor identification in patients with Parkinson's disease and multiple system atrophy. Mov Disord 2006;21:1975-1977.

25 Postuma RB, Lang AE, Massicotte-Marquez J, Montplaisir J: Potential early markers of Parkinson disease in idiopathic REM sleep behavior disorder. Neurology 2006;66:845-851.

26 Arnulf I, Leu-Semenescu S: Sleepiness in Parkinson's disease. Parkinsonism Relat Disord 2009;15(suppl 3):S101-S104.

27 Paus S, Brecht HB, Koester J, Seeger G, Klockgether T, Wuellner U: Sleep attacks, daytime sleepiness, and dopamine agonists in Parkinson's disease. Mov Disord 2003;18:659-667. 
28 Arnulf I, Konofal E, Merino-Andreu M, Houeto JL, Mesnage V, Welter ML, et al: Parkinson's disease and sleepiness: an integral part of PD. Neurology 2002;58:1019-1024.

29 Videnovic A, Noble C, Reid KJ, Peng J, Turek FW, Marconi A, et al: Circadian melatonin rhythm and excessive daytime sleepiness in Parkinson disease. JAMA Neurol 2014;71:463-469.

-30 Knie B, Mitra MT, Logishetty K, Chaudhuri KR: Excessive daytime sleepiness in patients with Parkinson's disease. CNS Drugs 2011;25:203-212.

31 Leentjens AF, Dujardin K, Marsh L, Martinez-Martin P, Richard IH, Starkstein SE: Symptomatology and markers of anxiety disorders in Parkinson's disease: a cross-sectional study. Mov Disord 2011;26:484-492.

-32 Shulman LM, Taback RL, Bean J, Weiner WJ: Comorbidity of the nonmotor symptoms of Parkinson's disease. Mov Disord 2001;16:507-510.

-33 Miyasaki JM, Shannon K, Voon V, Ravina B, Kleiner-Fisman G, Anderson K, et al: Practice parameter: evaluation and treatment of depression, psychosis, and dementia in Parkinson disease (an evidence-based review): report of the Quality Standards Subcommittee of the American Academy of Neurology. Neurology 2006;66: 996-1002.

-34 Devos D, Dujardin K, Poirot I, Moreau C, Cottencin O, Thomas P, et al: Comparison of desipramine and citalopram treatments for depression in Parkinson's disease: a double-blind, randomized, placebo-controlled study. Mov Disord 2008;23:850-857.

-35 Menza M, Dobkin RD, Marin H, Mark MH, Gara M, Buyske S, et al: A controlled trial of antidepressants in patients with Parkinson disease and depression. Neurology 2009;72:886-892.

36 Lemke MR: Dopamine agonists in the treatment of non-motor symptoms of Parkinson's disease: depression. Eur J Neurol 2008;15(suppl 2):9-14.

-37 Barone P, Poewe W, Albrecht S, Debieuvre C, Massey D, Rascol O, et al: Pramipexole for the treatment of depressive symptoms in patients with Parkinson's disease: a randomised, double-blind, placebo-controlled trial. Lancet Neurol 2010;9:573-580.

38 Giladi N, Treves TA, Paleancu D, Shabtai H, Orlov Y, Kandinov B, et al: Risk factors for dementia, depression and psychosis in long-standing Parkinson's disease. J Neural Transm 2000;107:59-71.

-39 Fabbrini G, Barbanti P, Aurilia C, Pauletti C, Lenzi, GL, Meco G: Donepezil in the treatment of hallucinations and delusions in Parkinson's disease. Neurol Sci 2002;23:41-43.

-40 Ondo WG, Tintner R, Voung KD, Lai D, Ringholz G: Double-blind, placebo-controlled, unforced titration parallel trial of quetiapine for dopaminergic-induced hallucinations in Parkinson's disease. Mov Disord 2005;20:958963.

-41 Klein C, Gordon J, Pollak L, Rabey JM: Clozapine in Parkinson's disease psychosis: 5-year follow-up review. Clin Neuropharmacol 2003;26:8-11.

42 O'Sullivan SS, Evans AH, Lees AJ: Dopamine dysregulation syndrome: an overview of its epidemiology, mechanisms and management. CNS Drugs 2009;23:157-170.

43 Voon V, Mehta AR, Hallett M: Impulse control disorders in Parkinson's disease: recent advances. Curr Opin Neurol 2011;24:324-330.

44 Emre M, Aarsland D, Brown R, Burn DJ, Duyckaerts C, Mizuno Y, et al: Clinical diagnostic criteria for dementia associated with Parkinson's disease. Mov Disord 2007;22:1689-1707.

45 Goldman JG, Holden S: Treatment of psychosis and dementia in Parkinson's disease. Curr Treat Options Neurol 2014;16:281.

46 McKeith IG, Dickson DW, Lowe J, Emre M, O’Brien JT, Feldman H, et al: Diagnosis and management of dementia with Lewy bodies: third report of the DLB consortium. Neurology 2005;65:1863-1872.

47 Rongve A, Vossius C, Nore S, Testad I, Aarsland D: Time until nursing home admission in people with mild dementia: comparison of dementia with Lewy bodies and Alzheimer's dementia. Int J Geriatr Psychiatry 2014; 29:392-398.

48 Chou KL, Evatt M, Hinson V, Kompoliti K: Sialorrhea in Parkinson's disease: a review. Mov Disord 2007;22: 2306-2213.

49 Van Camp G, Flamez A, Cosyns B, Goldstein J, Perdaens C, Schoors D: Heart valvular disease in patients with Parkinson's disease treated with high-dose pergolide. Neurology 2003;61:859-861.

50 Brooks DJ, Sagar H: Entacapone is beneficial in both fluctuating and non-fluctuating patients with Parkinson's disease: a randomised, placebo controlled, double blind, six month study. J Neurol Neurosurg Psychiatry 2003; 74;1071-1079.

-51 Stocchi F, Rascol O, Kieburtz K, Poewe W, Jankovic J, Tolosa E, et al: Initiating levodopa/carbidopa therapy with and without entacapone in early Parkinson disease: the STRIDE-PD study. Ann Neurol 2010;68:18-27.

52 Levitt P, Pintar J, Breakfield X: Immunocytochemical demonstration of monoamine oxidase B in brain astrocytes and serotonergic neurons. Proc Natl Acad Sci USA 1982;79:6385-6389.

53 The Parkinson Study Group: Effect of deprenyl on the progression of disability in early Parkinson's disease. N Engl J Med 1989;321:1364-1371.

54 Olanow CW, Rascol O, Hauser R, Feigin PD, Jankovic J, Lang A, et al; ADAGIO Study Investigators: A doubleblind, delayed-start trial of rasagiline in Parkinson's disease. N Engl J Med 2009;361:1268-1278.

55 Murata M, Hasegawa K, Kanazawa I; Japan Zonisamide on PD Study Group: Zonisamide improves motor function in Parkinson disease: a randomized, double-blind study. Neurology 2007;68:45-50. 
Mori A, Shindou T: Modulation of GABAergic transmission in the striatopallidal system by adenosine $A_{2 A}$ receptors: a potential mechanism for the antiparkinsonian effects of $\mathrm{A}_{2 \mathrm{~A}}$ antagonists. Neurology 2003; 61(suppl 6):S44-S48.

57 Hauser RA, Hubble JP, Truong DD; Istradefylline US-001 Study Group: Randomized trial of the adenosine A(2A) receptor antagonist istradefylline in advanced PD. Neurology 2003;61:297-303.

58 LeWitt PA, Guttman M, Tetrud JW, Tuite PJ, Mori A, Chaikin P, et al: Adenosine $\mathrm{A}_{2 \mathrm{~A}}$ receptor antagonist istradefylline (KW-6002) reduces 'off' time in Parkinson's disease: a double-blind, randomized, multicenter clinical trial (6002-US-005). Ann Neurol 2008;63:295-302.

59 Mizuno Y, Hasegawa K, Kondo T, Kuno S, Yamamoto M; Japanese Istradefylline Study Group: Clinical efficacy of istradefylline (KW-6002) in Parkinson's disease: a randomized, controlled study. Mov Disord 2010;25: 1437-1443.

60 Mizuno Y, Kondo T; Japanese Istradefylline Study Group: Adenosine $A_{2 A}$ receptor antagonist istradefylline reduces daily OFF time in Parkinson's disease. Mov Disord 2013;28:1138-1141.

61 Fabbrini G, Brotchie JM, Grandas F, Nomoto M, Goetz CG: Levodopa-induced dyskinesias. Mov Disord 2007; 22:1379-1389.

62 Wolf E, Seppi K, Katzenschlager R, Hochschorner G, Ransmayr G, Schwingenschuh P, et al: Long-term antidyskinetic efficacy of amantadine in Parkinson's disease. Mov Disord 2010;25:1357-1363.

-63 Devos D; French DUODOPA Study Group: Patient profile, indications, efficacy and safety of duodenal levodopa infusion in advanced Parkinson's disease. Mov Disord 2009;24:993-1000.

64 Schapira AHV, Cooper JM, Dexter D, Jenner P, Clark JB, Marsden CD: Mitochondrial complex I deficiency in Parkinson's disease. Lancet 1989;i:1269.

65 Mizuno Y, Ohta S, Tanaka M, Takamiya S, Suzuki K, Sato T, et al: Deficiencies in complex I subunits of the respiratory chain in Parkinson's disease. Biochem Biophys Res Commun 1989;163:1450-1455.

66 Spillantini MG, Schmidt ML, Lee AMY, Trajanowski JQ, Jakes R, Goedert M: $\alpha$-Synuclein in Lewy bodies. Nature 1997;388:839-840.

-67 Devi L, Raghavendran V, Prabhu BM, Avadhani NG, Anandatheerthavarada HK: Mitochondrial import and accumulation of alpha-synuclein impair complex I in human dopaminergic neuronal cultures and Parkinson disease brain. J Biol Chem 2008;283:9089-90100.

68 Yasuda T, Nakata Y, Mochizuki H: $\alpha$-Synuclein and neuronal cell death. Mol Neurobiol 2013;47:466-483.

69 Wang H, Ghosh A, Baigude H, Yang CS, Qiu L, Xia X, et al: Therapeutic gene silencing delivered by a chemically modified small interfering RNA against mutant SOD1 slows amyotrophic lateral sclerosis progression. J Biol Chem 2008;283:15845-15852.

70 Boudreau RL, McBride JL, Martins I, Shen S, Xing Y, Carter BJ, et al: Nonallele-specific silencing of mutant and wild-type huntingtin demonstrates therapeutic efficacy in Huntington's disease mice. Mol Ther 2009;17: 1053-1063.

71 Singer O, Marr RA, Rockenstein E, Crews L, Coufal NG, Gage FH, et al: Targeting BACE1 with siRNAs ameliorates Alzheimer disease neuropathology in a transgenic model. Nat Neurosci 2005;8:1343-1349.

72 Nóbrega C, Nascimento-Ferreira I, Onofre I, Albuquerque D, Hirai H, Déglon N, et al: Silencing mutant ataxin-3 rescues motor deficits and neuropathology in Machado-Joseph disease transgenic mice. PLoS One 2013; 8:e52396.

73 Kumar P, Wu H, McBride JL, Jung KE, Kim MH, Davidson BL, et al: Transvascular delivery of small interfering RNA to the central nervous system. Nature 2007;448:39-43. 